\title{
Science feels the pinch as Bush budget targets defence
}

\section{Erika Check, Washington}

American science is set to be squeezed next year, after President George Bush proposed a budget aimed at holding down total spending while shifting emphasis to military and homeland-security needs.

Bush's proposal for the 2004 fiscal year, which begins on 1 October, would see the federal government spend a record $\$ 123$ billion on research and development $(\mathrm{R} \& \mathrm{D})$ with more than half of the money going to the Department of Defense (see chart, right). Outside the Pentagon, R\&D increases by about $4 \%$ - in line with the rest of the federal budget, but well short of the increases that science agencies have enjoyed in recent years.

Announcing the research portion of the budget on 3 February, John Marburger, director of the White House Office of Science and Technology Policy, said that it reflects the administration's primary concerns of securing the nation against terrorist and military threats. "Science and technology are essential to the defence effort," he said.

Congress has not yet passed the 2003 budget, so it is difficult to compare Bush's figures with current spending. But his 2004 proposal for the basic research component of the $R \& D$ budget calls for a $5 \%$ increase in spending over his 2003 request.

If Congress, as expected, increases some agency budgets by more than Bush asked for last year, funding next year at most science agencies would be flat or increase only slightly. Most of the requested new spending will go towards security-related programmes.

"This budget raises some serious questions about the administration's overall commitment to science and technology," says Mike Lubell, director of public affairs for the American Physical Society. "At best, we're treading water."

The National Institutes of Health, which in recent years received double-digit increases,

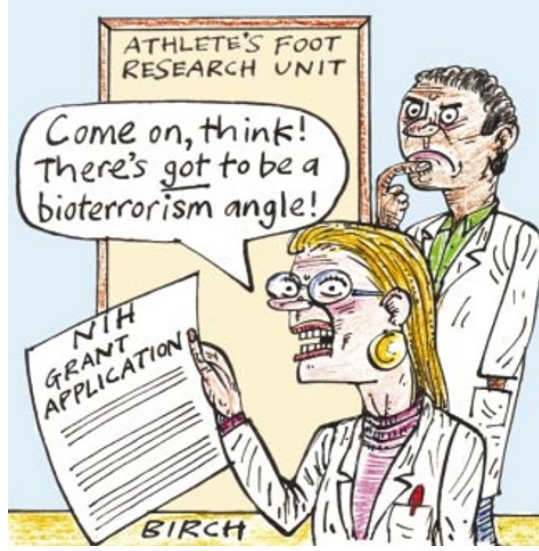

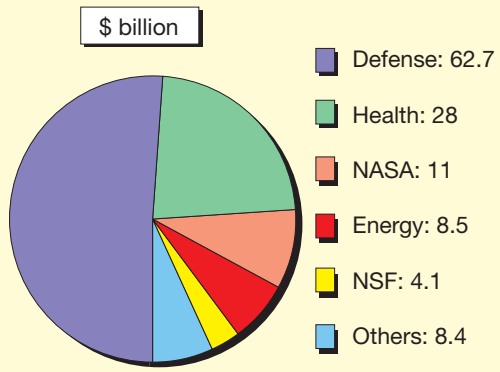

Fighting fit: the Department of Defense is the winner in Bush's 2004 R\&D budget proposal.

would get just a $2 \%$ increase over proposed funding for the current year. And although the president's request would double the number of biodefence-related grants to 660 , it would add just 21 new grants to the 9,827 that will be available this year for research not related to biodefence.

"We have to ask to what extent the biodefence mission is altering public-health outcomes," says April Burke of Washington lobbying firm Lewis-Burke Associates. "The fear factor is what is being funded in place of research that will make Americans healthier."

At the National Science Foundation (NSF), which funds most non-biomedical research at US universities, the proposal favours fields that could be applied to intelligence and counter-terrorism - including mathematics, which is boosted by around $50 \%$ to $\$ 89$ million, and research into 'human and social dynamics', which would grow almost threefold to $\$ 24$ million. But the NSF's overall budget - although 9\% more than what Bush proposed last year - would exceed the likely 2003 budget by just $2 \%$.

The Bush proposal would increase the Department of Energy's Office of Science which supports most US physicists - by just $1.4 \%$ over last year's request, to $\$ 3.3$ billion. High on the list of priorities for the science office is $\$ 12$ million in funding to support the international fusion experiment ITER, which the United States rejoined last week (see page 563). Computing, nanotechnology and microbial genomes would also do well.

When Congress finishes the 2003 budget, it will mull over Bush's proposal for 2004 . Law-makers are due to send budget bills back to Bush to sign in autumn. In the past they have often given more money to science than presidents asked for, but that might not happen this year. "There's very little incentive for a Republican-controlled Congress to break much with this administration," says Burke. Additional reporting by Geoff Brumfiel and Hannah Hoag.
Space research goes nuclear

An ambitious NASA budget proposal - crafted before the 1 February loss of the space shuttle Columbia - would make hefty investments in nuclear propulsion and high-energy astrophysics. Under the Bush proposal, NASA's budget would rise 3.1\% to $\$ 15.47$ billion in 2004 . The agency's nuclear-rocket initiative - now called Project Prometheus - would expand a programme that was restarted last year, spending $\$ 279$ million in 2004. This would fund a nuclear-propelled Jupiter Icy Moon Orbiter mission to search for subsurface oceans on the moons Europa, Ganymede and Callisto. The proposal also asks for $\$ 59$ million to set up a 'Beyond Einstein' astrophysics project, and \$39 million for developing fresh concepts and technologies for human space flight.

\section{Ebbs and flows at standards lab}

The Advanced Technology Program (ATP), a scheme to support early-stage industrial research and development, would end under the budget proposal.The Bush budget for the National Institute of Standards and Technology (NIST) would chop more than $\$ 100$ million from ATP's 2003 allocation, allotting just under $\$ 30$ million to wrap the programme up. But NIST would get $\$ 70$ million under the proposal to modernize and expand its main labs in Boulder, Colorado, and Gaithersburg, Maryland.

\section{Falls for basic defence research}

Despite massive expansion in the Department of Defense's efforts to develop new weapons systems, its spending on basic scientific research would be sharply curtailed under the budget proposal. Pentagon spending on basic research would fall by $8 \%$ to $\$ 1.3$ billion, and basic research spending at the Defense Advanced Research Projects Agency, which supports innovative and high-risk science, would drop by $25 \%$ to $\$ 150$ million. Meanwhile, the proposal expands the controversial ballistic missile defence programme by $17 \%$ to $\$ 7.7$ billion. The increase would allow development of new options for intercepting ballistic missiles and advanced radar systems to track incoming warheads, administration officials said.

\section{Food safety comes to the fore}

In a response to perceived threats from both animal diseases and terrorists, the Food and Drug Administration (FDA) and the US Department of Agriculture (USDA) would each get extra resources for food safety. The Bush proposal asks for $\$ 20.5$ million for food-safety programmes at the FDA, $\$ 10.5$ million of which would be used to start a registration system for food production, storage and shipping. The USDA also gets a $5.6 \%$ boost for food safety and $\$ 47$ million extra for lab security and research on animal diseases and vaccines. 